
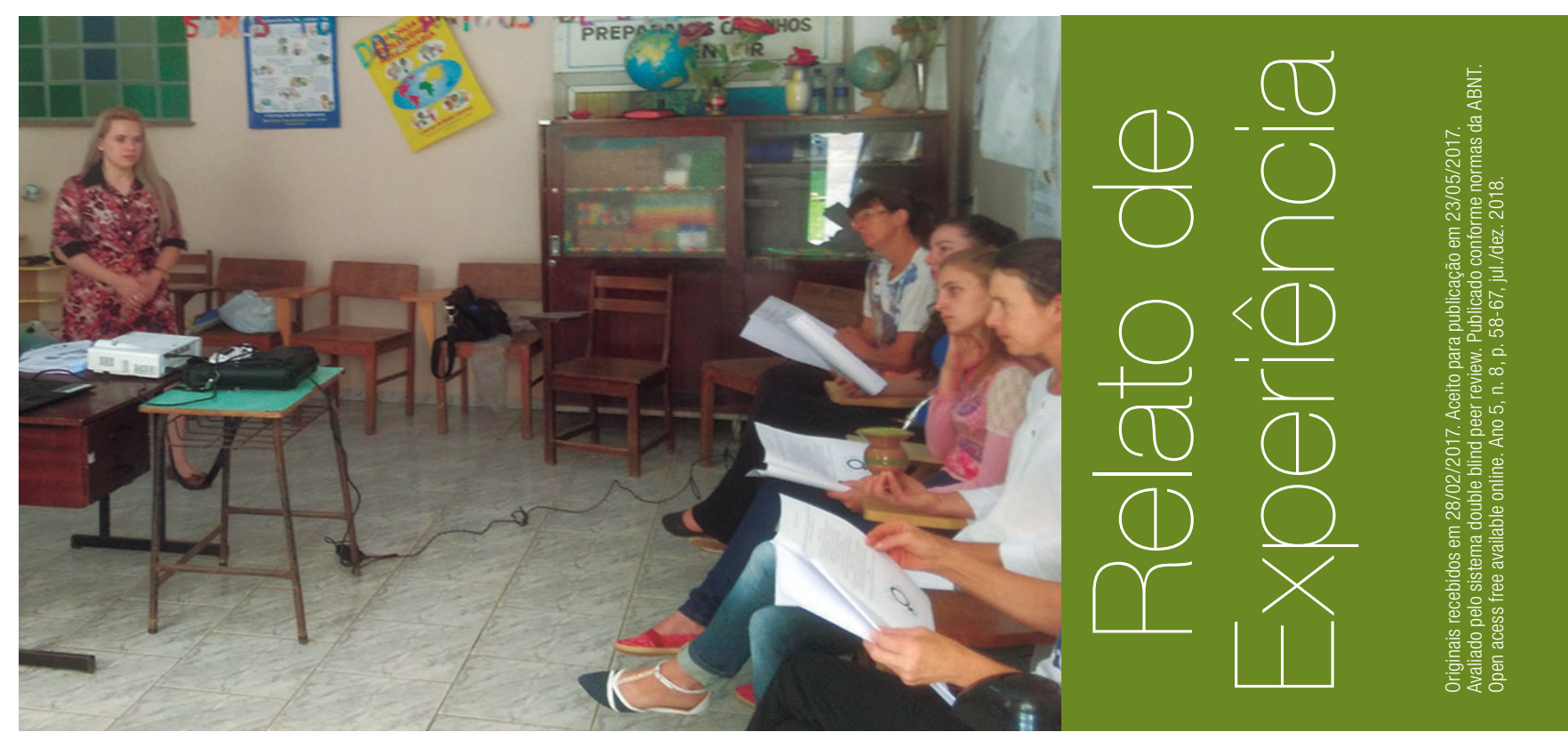

\title{
Segurança Alimentar e \\ Valorização do Protagonismo Feminino na Agricultura Familiar
}

\author{
Victória Luiza Schelbauer de Lima ${ }^{1}$ - victoriaschelbauer@gmail.com \\ Maiara Soares Fragoso 2 - fragosomaiara1@gmail.com \\ Vilson Cesar Schenato ${ }^{3}$ - vilson.cesar@ifsc.edu.br
}

\section{RESUMO}

Este relatório discute sobre uma experiência de projeto de extensão que tem como objetivo refletir sobre a desigualdade de gênero no meio rural e abordar questões de segurança alimentar. Na dinâmica produtiva da Agricultura Familiar, as mulheres têm conquistado mais espaço, porém, em muitos casos, ainda sofrem com a cultura machista que as coloca apenas como meras ajudantes nas atividades. Para atingir os objetivos do projeto, foram realizadas palestra, seguidas de entrevistas e discussões sobre 0 assunto.

\section{PALAVRAS-CHAVE}

Agricultoras. Atividades Rurais. Valorização da Mulher. Alimentação Segura.

\section{ABSTRACT}

This report discusses an extension project experience aimed at reflecting on gender inequality in rural areas and addressing food security issues. In the productive dynamics of family farming, women have gained more space, but in many cases still suffer from the sexist culture that places them only as mere helpers in activities. To achieve the project objectives, a lecture was held, followed by interviews and discussions on the subject.

\footnotetext{
1 Concluinte do Superior de Tecnologia em Alimentos (IFSC - Campus Canoinhas).

2 Concluinte do Superior de Tecnologia em Alimentos (IFSC - Campus Canoinhas).

3 Doutor em Ciências Sociais pela Universidade Federal de Campina Grande, professor da área de Ciências Humanas e Sociais, atuando em diversos cursos do Instituto Federal de Santa Catarina (IFSC - Campus Canoinhas).
} 


\section{KEYWORDS}

Women Farmers. Rural Activities. Appreciation of Women. Safe Feed.

\section{Relato de experiência}

0 objetivo deste projeto de extensão foi compartilhar conhecimentos com comunidades rurais, fazendo uma reflexão sobre a atividade produtiva das mulheres, bem como sobre sua condição feminina. Os minicursos foram organizados para numa primeira etapa abordar aspectos sobre a Segurança Alimentar e, logo em seguida, numa segunda etapa, estabelecer debates sobre direitos, a violência contra a mulher, machismo e as diferenças entre os gêneros no trabalho rural.

A divisão de gênero está agudamente ligada com as representações construídas socialmente, compartilhadas e socializadas favorecendo a dominação masculina que se impõe nas relações de gênero. Assim, no meio rural brasileiro, a figura masculina é tida como executora do trabalho pesado, enquanto a mulher realiza 0 trabalho doméstico e "auxilia" o marido no trabalho rural. Desta forma, no meio rural, assim como em outras áreas da sociedade, o homem é mais valorizado do que a mulher (PAULILO, 1982).

0 caminho metodológico se deu de início pelo levantamento bibliográfico sobre o tema. Em seguida houve a definição do público-alvo, tendo em vista o recorte de gênero e produtivo, ou seja, mulheres rurais que trabalham com a produção de alimentos. No estabelecimento dos primeiros contatos com as localidades rurais do município de Canoinhas, houve de início certa dificuldade para a participação das mulheres, visto que, entre os meses de fim de ano, a lavoura de fumo demanda muito trabalho de toda a família, inclusive das mulheres. Apesar das dificuldades, foi possível reunir agricultoras interessadas nas seguintes comunidades rurais: Salto da Água Verde, Forquilha e Rio do Pinho. No total foram 20 (vinte) participantes que trocaram conhecimentos, interagiram, contaram suas experiências e histórias ligadas à condição feminina.

Sob a coordenação do Prof. Dr. Vilson Cesar Schenato foi elaborado e aplicado um minicurso de 4 horas em cada uma das localidades, dividido em quatro momentos e realizado de forma verbal, através de debates, meios audiovisuais, slides e atividades práticas demonstrativas, estimulando a participação ativa do público, que, apesar da timidez inicial, iam, aos poucos, se soltando e se envolvendo nas discussões.

A primeira parte do minicurso nas comunidades foi uma breve introdução sobre o projeto de extensão e a aplicação de questionário prévio para conhecer melhor o perfil das agricultoras do projeto, principalmente nos aspectos produtivos dentro do meio rural e sobre as suas relações familiares e de gênero. Foi possível constatar que as agricultoras trabalham em todas as fases do ciclo produtivo do fumo, desde o plantio até a sua colheita e secagem nas estufas. Além disso, elas produzem alimentos em conserva, biscoitos e derivados lácteos para incrementar a renda familiar, atividades que podem ser entendidas como estratégias de resistência à dominação masculina, pois se constituem em rendas alternativas ao fumo, elevando a autonomia das mulheres pesquisadas nas entrevistas.

Desta forma, destaca-se a importância da segunda parte do minicurso, na qual foi realizada uma palestra sobre Segurança Alimentar e Boas Práticas de Fabricação aplicadas aos produtos mais produzidos por elas. Tais conhecimentos foram proveitosos, tendo em vista que cerca de $80 \%$ das agricultoras participantes nunca tiveram a oportunidade de realizar cursos de aperfeiçoamento na área. Naquela ocasião, as dúvidas foram sanadas e era perceptível 0 interesse das participantes em buscar mais conhecimento relacionado ao tema.

A capacitação e os conhecimentos adquiridos agregam valor ao trabalho e elevam o nível de qualidade dos produtos por elas produzidos, além de auxiliar no desenvolvimento intelectual de cada uma.

A terceira parte do minicurso foi uma palestra sobre 0 trabalho da mulher dentro da Agricultura Familiar, abordando 0 acesso às políticas públicas e aos direitos das mulheres. Em seguida, abriu-se para debates, troca de informações e depoimentos acerca do protagonismo feminino, o homem e a sua posição de liderança, serviços domésticos, desigualdades reforçadas pelo 
machismo, preconceitos e a falta de reconhecimento da mulher na agricultura e em geral. Podese notar que muitas delas não são valorizadas no trabalho que fazem "fora" de casa, pois tais atividades, principalmente na lavoura, são vistas como "ajuda", ou seja, apenas como atividades secundárias e que "auxiliam" a figura masculina.

Historicamente para homens e mulheres foram reservados lugares sociais desiguais na sociedade e essa assimetria é sinônimo de opressão para com as mulheres. Além disso, as mulheres da classe trabalhadora sofrem ainda mais, pois existe ainda distinção entre elas e as mulheres da classe burguesa (TOLEDO, 2005 apud GONÇALVES et al., 2015). Ao pensar a realidade rural, a condição feminina fica ainda mais precária, pois as dificuldades de acesso a serviços e direitos básicos de cidadania são ainda maiores.

Cada localidade, apesar da proximidade territorial, apresentou as suas particularidades. Na localidade do Salto da Água Verde (Figura 1), todas as agricultoras produzem conservas e geléias e realizam os trabalhos domésticos. Quando questionadas sobre a participação dos maridos na execução destas atividades, apenas uma afirmou que este divide as tarefas com ela. Em relação às decisões no interior da família, afirmou que o homem decide sobre as questões da lavoura e a mulher sobre as questões da casa.

Uma participante relatou que já sofreu violência doméstica e outra afirmou que mesmo fazendo as mesmas atividades, e às vezes até mais, sempre foi vista como "ajudante" do marido.

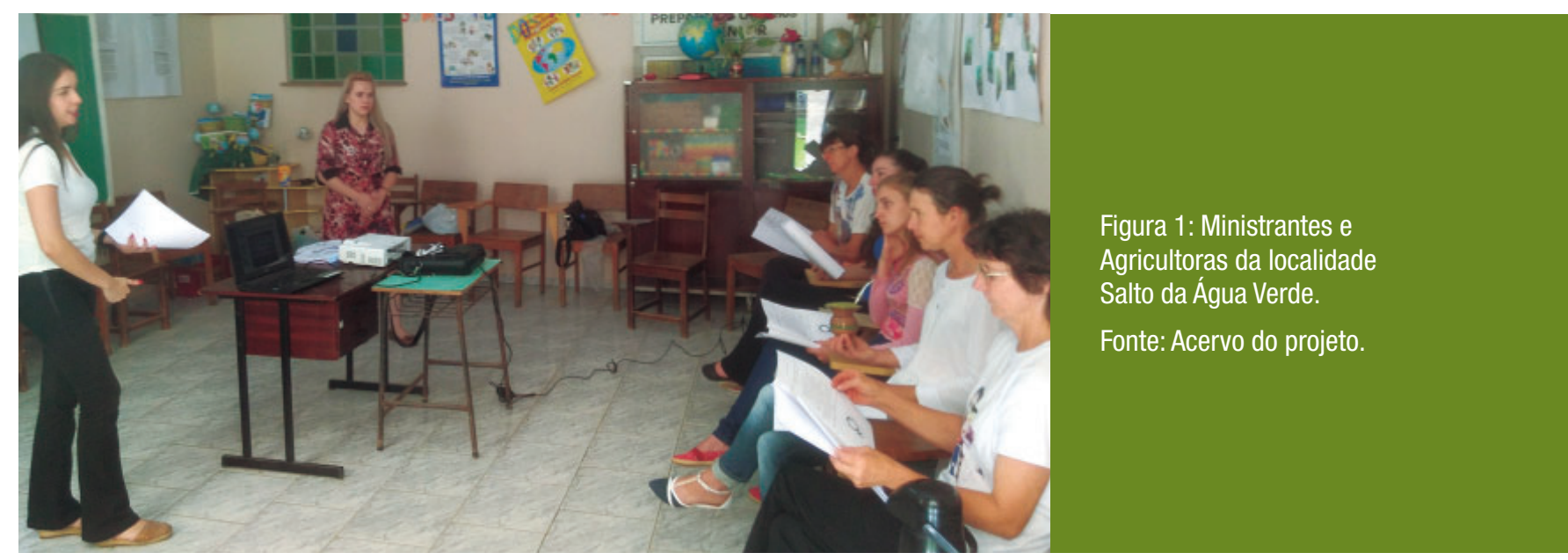

Na localidade da Forquilha (Figura 2) cerca de $60 \%$ das agricultoras relataram que as decisões, tanto da casa quanto da lavoura, são tomadas por toda a família. Uma delas expôs que na sua casa os afazeres domésticos ficam por conta das mulheres e que estas ainda realizam atividades na lavoura, destacando que realizam muitas atividades e raramente são valorizadas por isso. As demais participantes não relataram experiências, porém concordaram com o relato.

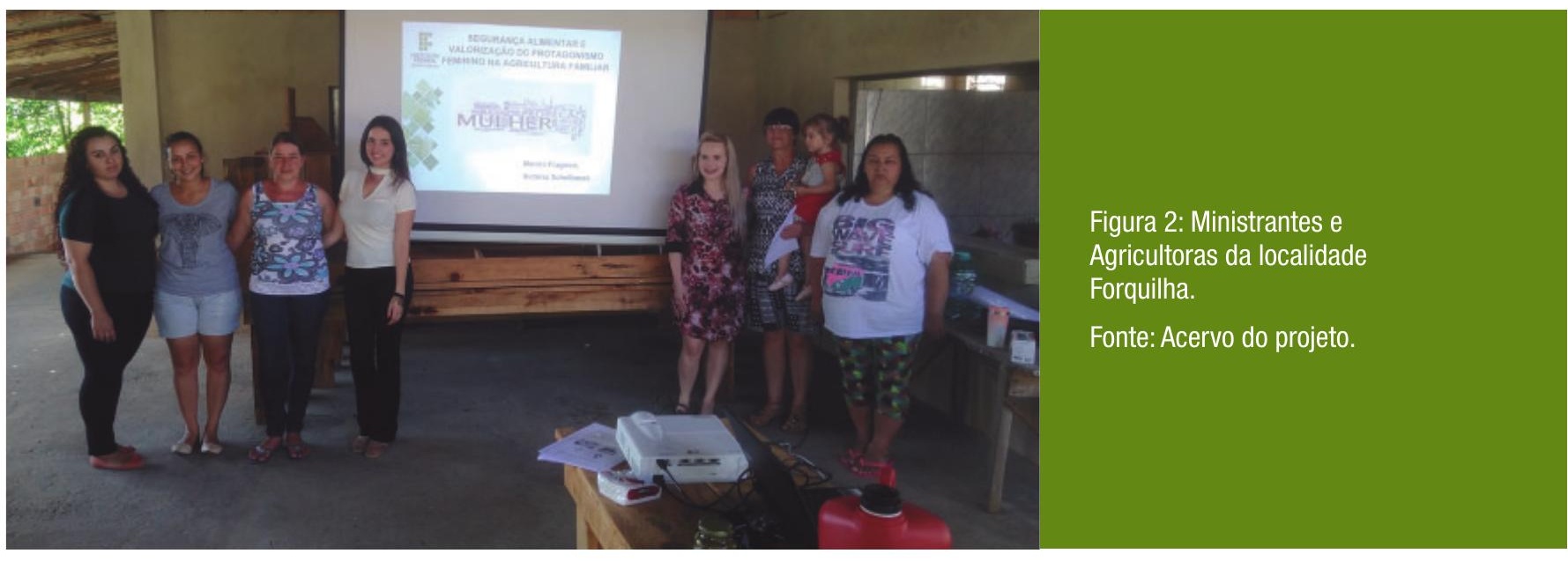


Na localidade de Rio do Pinho (Figura 3) todas relataram produzir conservas, já em relação à tomada de decisões em casa e na lavoura, algumas responderam que o marido toma todas as decisões e outras relataram que as decisões da lavoura são centralizadas no marido e as decisões relacionadas a casa ficam por conta das mulheres. Não houve nenhum tipo de relato relacionado à violência, entretanto, todas concordaram que a mulher não é valorizada da maneira que deveria e que o homem, na maioria das vezes, possui privilégios, que são restrições para as mulheres, tais como: sair à noite e encontrar os amigos.

Figura 3: Ministrantes e Agricultoras da localidade Rio do Pinho. Fonte: Acervo do projeto.

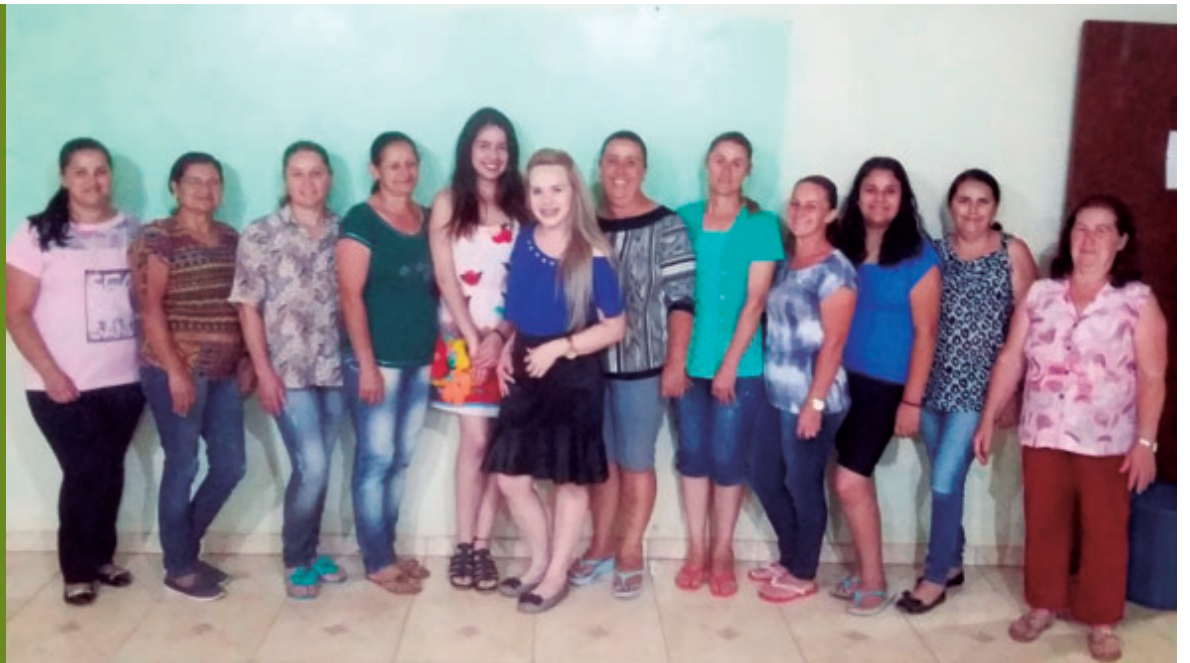

Nos questionários, ao pedir para enumerarem o que as suas famílias mais valorizam em relação ao trabalho realizado por elas, o que mais aparece nas respostas é: $1^{\circ}$ fazer comida, $2^{\circ}$ limpar e arrumar a casa, $3^{\circ}$ lavar roupa; seguidos de trabalhos "fora de casa" como: cuidar / tratar animais, trabalhar na horta, cuidar do jardim e trabalhar na lavoura. As respostas delas podem indicar que, no universo social desigual em que vivem, os outros membros da família veem como mais importantes as atividades das mulheres no espaço doméstico da casa e adjacências. A lavoura é representada socialmente como o espaço masculino por excelência e os rendimentos ali ganhos ficam geralmente sob o controle do homem.

Com base no projeto de extensão, nota-se que a cultura machista permanece no meio rural do Planalto Norte Catarinense, fazendo com que as agricultoras familiares trabalhem de forma igual, mas sejam vistas apenas como "ajudantes" no campo, o que resulta no enfretamento de inúmeras opressões resultantes da desigualdade de gênero. Tais questões serão aprofundadas em um futuro projeto de pesquisa.

Figura 4: Coordenador do Projeto, Ministrantes e Agricultoras de Rio do Pinho.

Fonte: Acervo do projeto.

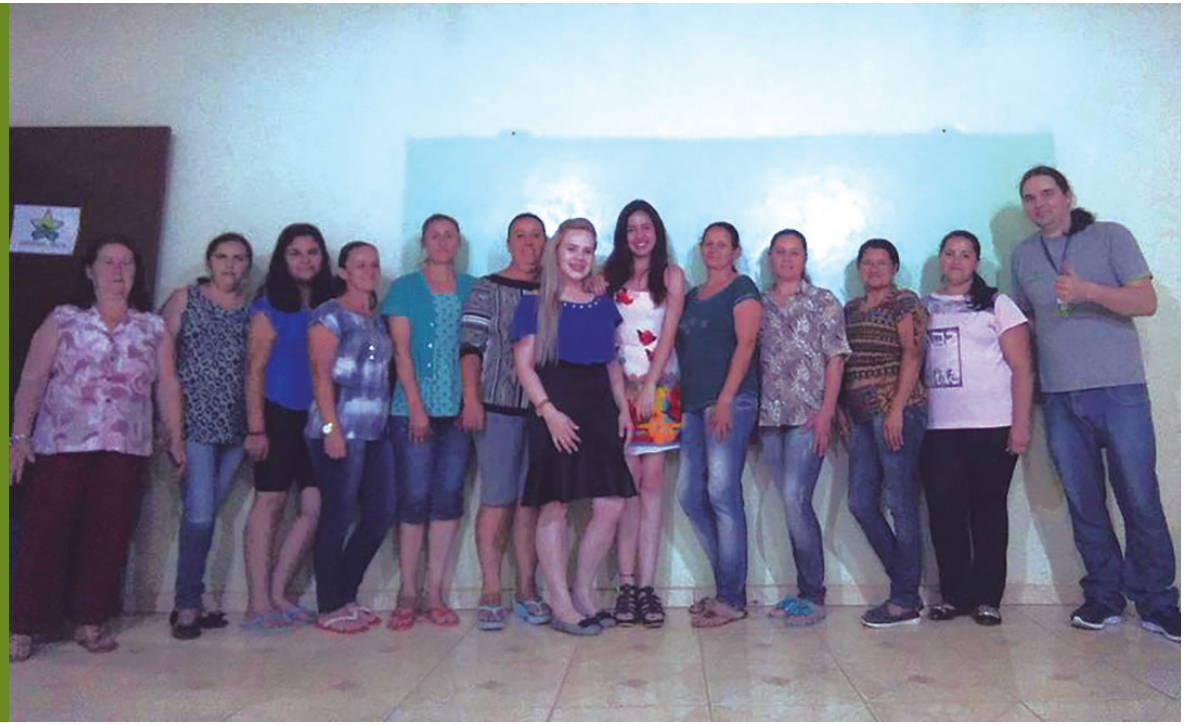


A troca de saberes dentro da ação extensionista promoveu a reflexão e aprendizagem coletiva. Foram debates enriquecedores que fizeram com que todas as participantes saíssem pensando diferente dos minicursos. São reflexões como estas que podem contribuir para o empoderamento feminino na sociedade mais ampla e também nas comunidades rurais, diminuindo a desigualdade de gênero nas tarefas domésticas e da propriedade familiar como um todo.

Por fim, o projeto possibilitou a aproximação e interação do IFSC com a comunidade local, através dos extensionistas, agregando conhecimento para professor, bolsistas e agricultoras. A rede de contatos que se estabeleceu permite que futuramente possamos desenvolver novos trabalhos com as agriculturas e /ou as comunidades a que pertencem.

\section{Referências}

GONÇALVES, Micheli Suellen Neves; MOLINA, Mônica Castagna; CORDEIRO, Georgina Negrão. Gênero e Constituição da Mulher Camponesa: Um estudo das Produções Acadêmicas sobre Gênero na formação proposta pela Educação Superior do Campo no Brasil de 2011 a 2015. Universidade Estadual de Maringá. 2016.

PAULILO, Maria Ignez S. 0 Peso do Trabalho Leve. Ciência Hoje, n. 28, 1987.

TOLEDO, C. Mulheres o gênero nos une, a classe nos divide. São Paulo: Instituto José Luís e Rosa Sundermann, 2005. 